\title{
FOUCAULT: UN MODO PARADÓJICO DE HACER FILOSOFÍA
}

\author{
Daniel Toscano López ${ }^{1}$
}

\section{RESUMEN:}

En este artículo nos proponemos caracterizar el modo paradójico y excéntrico de indagación filosófica propio del filósofo francés Michel Foucault. Esto se hará en tres momentos: en el primero, se formula el lugar que ocupan el poder, la subjetividad y la verdad en el periplo intelectual de este autor. En este sentido, la tarea filosófica del pensador francés es, por un parte, la de comprender de qué modo han sido producidos nuestros modos concretos de vivir, creer y pensar y, por otra, la de crearnos a nosotros mismos como una obra de arte; en el segundo, se propone la paradoja y la rareza como notas características de sus investigaciones, y cuya imagen que más las ejemplifica es la del cangrejo. Para explicar este carácter paradójjico son ilustrativos tanto el ejercicio de investigación del historiador Paul Veyne como el estilo singular del pintor René Magritte. Finalmente, y en el tercero, se plantea el elogio a la franqueza efectuado por Michel Foucault, cuya figura emblemática es la del parresiastés. Por eso, una característica paradójica de la personalidad de Foucault puede analizarse en uno de los términos que acuña: el de parresiastés, porque tal noción, entraña el riesgo para sí mismo que comporta el decir "esto", "aquello" o "lo otro", pues se trata de un decir franco, libre que adopta la forma de la crítica hacia sí mismo y hacia otros. En suma, la investigación paradójica y "rara" del pensador francés que procede por rupturas y discontinuidades conduce a entender nuestro presente y aquello que somos dentro de una perspectiva crítica que pregunta por las tecnologías y dispositivos políticos de poder que históricamente han contribuido a forjar nuestra subjetividad.

Palabras-clave: Foucault; Paradoja; Ontología del presente; Cuidado de sí; parresiastés.

\section{FOUCAULT: A PARADOXICAL WAY OF DOING PHILOSOPHY}

\begin{abstract}
:
In this article we propose to characterize the paradoxical and eccentric mode of philosophical inquiry proper of the French philosopher Michel Foucault. This will be done in three moments: in the first, the place occupied by power, subjectivity and truth in the intellectual journey of this author is formulated. In this sense, the philosophical task of the French thinker is, on the one hand, to understand how our concrete ways of living, believing and thinking have been produced and, on the other, to create ourselves as a work of art; in the second, paradox and rarity are proposed as characteristic features of his research, and the image that most exemplifies is that of the crab. To illustrate this paradoxical character, both the research exercise of the historian Paul Veyne and the singular style of the painter René Magritte are illustrative. Finally, and in the third, the praise is expressed for the frankness carried out by Michel Foucault, whose emblematic figure is that of the parrhesiastes. For that reason, a paradoxical characteristic of Foucault's personality can be analyzed in one of the terms he coined: that of parrhesiastes, because such a notion entails the risk for himself that implies saying "this", "that" or "the other ", Because it is a frank, free saying that takes the form of criticism towards oneself and towards others. In sum, the paradoxical and "rare" research of the French thinker that comes from ruptures and discontinuities leads us to understand our present and what we are within a critical perspective that asks about the technologies and political devices of power that historically have contributed to forge our subjectivity.
\end{abstract}

Key words: Foucault; Paradox; Ontology of the present; Self-care; Parresiastés.

\footnotetext{
${ }^{1}$ Asistente de investigación jurídica, Centro de bioética, Facultad de Medicina, Clínica Alemana, Universidad del Desarrollo. Doctor en Filosofía de la Pontificia Universidad Católica de Chile. E-mail: dtoscano@udd.cl
} 


\section{Introducción}

El pensamiento de Foucault (1926-1984) al ser plural, es decir al adoptar en el seno de su investigación tanto diversos tópicos como el neoliberalismo, la biopolítica, la gubernamentalidad, la locura, las instituciones, el Estado, la sociedad civil, entre otros, como un repertorio de métodos como la arqueología, la genealogía, el nominalismo, podría ser interpretado inmediatamente como excéntrico y extraño. Es bien sabido que su periplo intelectual está permeado por rupturas, desplazamientos y rectificaciones, siendo éstos aspectos constitutivos de un estilo propio de filosofar que colisiona con formas más sistemáticas de investigación. Por esto mismo Foucault es quien advierte en los cursos del Collège de France en el año 1976, bautizados con los nombres de Defender la sociedad o Genealogía del racismo, que el paradigma reinante de hacer investigación es el equiparable a

Un cachalote que salta por encima del agua y deja en ella una pequeña huella
transitoria de espuma, y que permite creer, hace creer o quiere creer, o bien
tal vez cree efectivamente que por debajo, donde ya no se lo ve, donde ya
nadie lo percibe ni lo controla, sigue una trayectoria profunda coherente y
meditada (FOUCAULT, 2001, p. 27).

El pensador francés será categórico en discrepar con este modelo, por lo cierto utópico e inexistente, porque supone que una investigación de cuño filosófico debería estar vacunada contra eventuales reformulaciones y cambios en su orientación. Por ende, para tal concepción, solo una verdadera investigación es aquella en la que existe una sistematización de conjunto, coherente y profunda, pues todo lo demás da al traste con lo que podría ser un legítimo ejercicio filosófico. Por consiguiente, es desde este enfoque "de mirada del cachalote" que se erige un primer prejuicio frente a Foucault y que declara que su reflexión no es filosófica por el hecho de que su modo de investigación es fragmentada, llena de rupturas y discontinuidades. A lo anterior, puede también sumarse, el hecho de que, a primera vista, fenómenos como el poder, el Estado, la sociedad civil, la población, al ser tradicionalmente estudiados por el discurso de la ciencia política, o al ser abordados por disciplinas diversas como la educación, la sociología, la antropología y el derecho, no son de la competencia directa de la filosofía, y por esta razón es que puede llegar a pensarse que el trabajo de Foucault se ocupa de asuntos que no atañen directamente a la filosofía como disciplina. En suma, como un segundo prejuicio, a este autor se le toma precipitadamente por alguien que vaga a la deriva al enfrentarse a cuestiones tan variopintas. La impresión de una investigación como la de Foucault, desperdigada y fragmentada, para nada compacta y coherente,

\begin{tabular}{|l|l|l|l|l|}
\hline Q Rovista Dialectus & Ano 4 & n. 11 & Agosto - Dezembro 2017 & p. 11-28 \\
\hline
\end{tabular}


confeccionan la imagen del intelectual que expone una sarta de incongruencias y de ideas deshilvanadas que no conducen a parte alguna.

El modo singular en el que el pensador francés acomete sus indagaciones, en ocasiones suscita el prejuicio que está relacionado con aquello que, a tenor de estudiosos de su obra, como Vázquez García señalan con respecto a él, y es que “todavía más de uno se resiste a incluir en el panteón de los filósofos” (VÁZQUEZ, 1995, p. 11). En virtud de lo anterior es menester emprender un ejercicio de "tratamiento" y análisis de dichos prejuicios que permita desembarazarse de esas imágenes previas acerca del modo en que Foucault acomete sus investigaciones. Para llevar a buen término esta tarea, en primer lugar vale la pena hacer hincapié en un escenario común de la filosofía Moderna, aquello que Spinoza y Bacon recomiendan a modo de precaución metodológica antes de aventurarse en cualquier investigación. En el primer caso, como resultado de su consagración al trabajo artesanal como pulidor de cristales para lentes de microscopios y telescopios, Spinoza advirtió que era importante "limpiar el cristal del entendimiento", pues esto redundaría enormemente en rectificar imágenes, pasiones o, incluso, ideas confusas e inadecuadas, mediante el proceder correctivo de la razón. De forma similar, en Francis Bacon puede rastrearse un ejercicio filosófico en el que "el primer esfuerzo del espíritu debe consistir en librarse de los prejuicios, puesto que se interponen entre él y las cosas. A estos prejuicios los llama ídolos, y Bacon encuentra cuatro clases" (VERNEAUX, 1989, p. 122).

Desde la perspectiva del filósofo de Poitiers se puede decir que, precisamente, si su producción intelectual es replanteada continuamente, y que, además, procede adentrándose en asuntos como el mercado, el neoliberalismo, la escuela, el manicomio, la sexualidad, entre otras, en esto estriba una de sus bondades. Por una parte, es desde las reorientaciones y replanteamientos que van surgiendo como problemas que se ponen en el centro del análisis asuntos como el poder disciplinario o la biopolítica y, por otra, tal actitud de volver reiteradamente sobre caminos que parecen trillados no es otra cosa que un ejercicio filosófico y de continua crítica en relación con «lo dado».

Así mismo, el carácter discontinuo y asistemático de sus reflexiones dista de ser un defecto o limitación, antes bien, hace parte de la estrategia metodológica llevada a cabo por el pensador francés, ya que con esto evita la tentación de caer por la pendiente resbaladiza de un discurso con pretensiones de universalidad, de carácter hermético, dogmático y absoluto. Por esto, la imagen en Foucault que mejor retrata la

\begin{tabular}{|l|l|l|l|l|}
\hline Q Rovista Dialectus & Ano 4 & n. 11 & Agosto - Dezembro 2017 & p. 11-28 \\
\hline
\end{tabular}


particularidad de su método, no es la del cachalote, sino como lo subraya en los cursos del Collège de France del año 1979 en Nacimiento de la biopolítica: "soy como el cangrejo, me muevo lateralmente“ (FOUCAULT, 2007, p. 96). Los movimientos del "cangrejo" que ilustran un modo fragmentario, repetitivo, discontinuo y, en último término, paradójico de la investigación de Foucault no dejan de ser por ello una reflexión ordenada y laboriosa, que va hilando lo más fino posible.

\section{Foucault: pensar nuestro propio presente}

Kant a finales del siglo XVIII escribía en un periódico alemán -el Berliner Monatschrift- el célebre ensayo «Washeisst Aufklärung?- Qué es la Ilustración». Allí indagaba acerca de su propio presente. En tal contexto kantiano, la filosofía recibe una nueva tarea: como dirá el mismo Foucault, la de reflexionar, no sólo el sistema metafísico o los pilares del conocimiento científico, sino también la de pensar un evento histórico, es decir a nosotros mismos y a nuestro presente.

Para Foucault, siguiendo en este punto la tradición kantiana, una de las preguntas más importantes a investigar desde la óptica histórica-filosófica, y que reviste la forma de una «ontología del presente», es aquella que interroga por ¿quiénes somos nosotros? Es decir, aquella que interpela por el modo en que hemos llegamos a ser lo que actualmente somos. Si se la analiza a la luz de nuestra actualidad, dicha inquietud está vigente, por cuanto aquello que somos individual y colectivamente no se reduce a un origen primero, sagrado y puro (Ursprung), que nos haya determinado inexorablemente a ser lo que hoy somos, sino que se trata de aquellos mecanismos y prácticas históricas que van esculpiendo nuestra subjetividad. En otras palabras, la tarea filosófica de Foucault, que no es la de la fundamentación, apunta a preguntar por las condiciones históricas, conceptuales y específicas que dan cuenta de "cómo hemos sido atrapados en nuestra propia historia" y nos lanza al desafío de comprender cómo han sido producidos e inventados (Erfindung) nuestros modos concretos de vivir, creer y pensar.

En relación con nuestros modos concretos de vivir, creer y pensar, Foucault se referirá a la importancia de «estilizar»o darle forma a la propia vida, esto es a la importancia surgida de la preocupación por crearnos a nosotros mismos como una «obra de arte». Se trata de un interrogante que parte del hecho de estar situados en una sociedad que relaciona el arte con los objetos pero no con la vida de los individuos. Es el mismo filósofo francés que lo plantea en los siguientes términos:

\begin{tabular}{|l|l|l|l|l|}
\hline Q Rovista Dialectus & Ano 4 & n. 11 & Agosto - Dezembro 2017 & p. 11-28 \\
\hline
\end{tabular}


Lo que más me impacta es que en nuestra sociedad, el arte se haya vuelto algo que se relaciona sólo con los objetos, y no con los individuos o con la vida (...) ¿pero la vida de cada individuo no podría volverse acaso una obra de arte? ¿Por qué un cuadro o una casa pueden volverse objetos de arte, pero no nuestra vida?" (FOUCAULT, 1994, p. 617).

Para el profesor de los cursos del Collège de France, pensar nuestro propio presente significa emprender la compleja tarea de trazar una historia de varios tipos de familias de tecnologías políticas de poder que han dado forma a lo que actualmente somos. Pues, así como desde el seno de la Edad Moderna han venido proliferando hasta el presente distintas revoluciones de tipo industrial y científico, así como el desarrollo de múltiples estrategias que producen el sentido de la existencia humana, existe otro tipo de tecnologías, no menos importantes, cuya emergencia en el pensamiento occidental juegan un papel importante en lo que autores como Hurtado Valero (1994) han dado en llamar «ontología del presente». Estas familias de tecnologías son las políticas, desarrolladas en los siglos XVII y XVIII.

En el texto Tecnologías del yo, el cual es el fruto de la conferencia dictada durante el otoño de 1982, en la Universidad de Stanford, el filósofo de Poitiers pone de relieve cuatro tecnologías: las de producción y transformación de cosas; las de sistemas de signos; las de poder; finalmente, las tecnologías del yo (FOUCAULT, 1996, p. 48). En suma, las dos últimas son abordadas por Foucault, pues las dos primeras han sido trabajadas por las ciencias y la lingüística respectivamente. El pensador francés pondrá el acento en las dos tecnologías inéditas mencionadas, desarrolladas históricamente en los siglos XVII y XVIII, porque la «tecnología del poder» le permite entender cómo es que se lleva a cabo la subjetivación de los individuos, mientras que las «tecnologías del yo» le reportan la utilidad de investigar cómo se efectúa la transformación de «uno mismo». En una entrevista realizada por Raúl Fornet Betancourt y Alfredo GómezMüller, Foucault hace hincapié en una quinta familia de tecnologías denominadas gubernamentales, las cuales articulan las «tecnologías de poder o de dominación» con las «tecnologías del yo»:

$\mathrm{Y}$ entre ambos, los juegos de poder y los estados de dominación, se encuentran las tecnologías gubernamentales (...) El análisis de estas técnicas es necesario porque, con frecuencia, a través de este género de técnicas es como se establecen y se mantienen los estados de dominación (FOUCAULT, 1999, pp. 413-414).

Aunque en el seno de estas tres tecnologías mencionadas, las del poder, las del yo y las gubernamentales está atravesado el problema de la biopolítica, es en el primer

\begin{tabular}{|c|c|c|c|c|}
\hline Q Ronita Oialectus & Ano 4 & n. 11 & Agosto - Dezembro 2017 & p. $11-28$ \\
\hline
\end{tabular}


volumen de Historia de la sexualidad: la voluntad de saber, donde ésta se plantea en los siguientes términos:

El establecimiento, durante la edad clásica, de esa gran tecnología de doble faz- anatómica y biológica, individualizante y especificante, vuelta hacia las relaciones del cuerpo y atenta a los procesos de la vida- caracteriza un poder cuya más alta función no es ya matar sino invadir la vida enteramente (FOUCAULT, 1976, p. 235).

Es en este escenario de tecnologías del poder (disciplinarias y biopolítica) que en el filósofo francés late la preocupación por las prácticas modernas que inventan la subjetividad y también la pregunta por las estrategias que se han de desplegar frente a dichas prácticas modernas de subjetivación. Ante el creciente fenómeno de administración y burocratización de la vida, Foucault propone como válvula de escape la «estética de la existencia», entendiendo por ésta la «ética del cuidado de sí» en tanto que práctica de la libertad. Se trata, entonces, de la libertad que los individuos ejercen cuando son capaces de construir la propia existencia con arreglo a criterios estéticos. Como lo señala Ortega: "Foucault dirige su atención a las prácticas de sí, o sea, a las diferentes herramientas que los individuos poseen para constituirse y reescribir constantemente sus identidades" (ORTEGA, 2000, p. 29). Ahora bien, la expresión "cuidado de sí" en el autor francés tiene como telón de fondo las nociones de poder, verdad y saber. En otras palabras, el cuidado de sí emerge de una preocupación que relaciona el poder, la verdad y el saber como elementos que, aunque distintos, son complementarios de cara a responder a aquello que el pensador francés considera es el objetivo que persigue desde hace veinticinco años, el cual consiste en:

Trazar una historia de las diferentes maneras en que, en nuestra cultura, los hombres han desarrollado un saber acerca de sí mismos: biología, psiquiatría, medicina y penología. El punto principal no consiste en aceptar este saber como un valor dado, sino en analizar estas llamadas ciencias como "juegos de verdad" específicos, relacionados con técnicas específicas que los hombres utilizan para entenderse a sí mismos (FOUCAULT, 1996, p. 48).

Foucault indaga el asunto de la verdad en relación con el problema del saber y del sujeto. No es que la verdad se sitúe en una posición privilegiada y superior de exterioridad por encima del saber y el poder. Antes bien, lo que sorprende al filósofo francés es el hecho de cómo es posible la verdad cuando ésta se produce históricamente, cuando la verdad emerge de prácticas institucionales y en el marco de relaciones de poder-saber que afectan al sujeto y a la conducta ética de éste. Es por esto que, antes que preguntarse por la verdad, Foucault emprende una «ontología del presente» que investiga las condiciones histórico, sociales y epistemológicas, lo cual incluye

\begin{tabular}{|c|c|c|c|c|}
\hline Rovita Oidectus & Ano 4 & n. 11 & Agosto - Dezembro 2017 & p. $11-28$ \\
\hline
\end{tabular}


relaciones de poder y saber, que hacen posible la "experiencia" de los sujetos, con la correspondiente constitución de la subjetividad. Por eso es que, siguiendo a Revel, para el filósofo de Poitiers: "no hay constitución de subjetividad fuera de una relación con la verdad" (REVEL, 2005, p. 49), razón por la cual, la verdad es productora de subjetividad, pero la verdad es en la experiencia propia una ficción fabricada a partir de algo que no existía antes.

Por eso también el pensador francés gira desde una concepción sustancialista del sujeto hacia otra pragmática en la que el sujeto se constituye a sí mismo. En consecuencia, la tarea de Foucault dice relación con la articulación tanto de una «ontología del presente» con una analítica de la verdad. En otras palabras, la tarea consiste en identificar las relaciones entre los juegos de verdad, las relaciones de poder y los modos en que los sujetos se relacionan consigo mismos y con los otros. Por consiguiente, el trabajo genealógico de Foucault busca restablecer las formas a partir de las cuales nos transformamos en lo que somos e indaga por las experiencias en virtud de las cuales nos constituimos en sujetos políticos, éticos, de conocimiento. Esto implica que la «verdad» es para él «historia política de la verdad». Por eso, en este autor, el asunto de la verdad no deja de ser complejo y reviste matices de acuerdo al conjunto de temas y problemas a los que va plantando cara.

Mientras que el Foucault más "arqueológico", cuyas obras comprenden la década de los 50s y 60s, liga más la verdad con la problemática epistemológica del saber y de los discursos, en los 70s, el Foucault más genealógico conecta a la verdad con el saber y el poder. Finalmente, el último Foucault, el de la ética, hará hincapié en el «cuidado de sí», es decir en la necesidad de dar estilo a la propia vida, como destrucción de la «inmunización de la verdad», tal como puede evidenciarse en El coraje de la verdad. Para Foucault:

El cinismo liga el modo de vida y la verdad de una manera mucho más
estrecha, mucho más precisa. Hace de la forma de la existencia una condición
esencial para el decir veraz. Hace de la forma de la existencia la práctica
reductora que va a dejar lugar al decir veraz. Y, para terminar, hace de la
forma de la existencia un medio de hacer visible, en los gestos, en los
cuerpos, en la manera de vestirse, en la manera de conducirse y de vivir, la
verdad misma. En suma, el cinismo hace de la vida, de la existencia, del bíos,
lo que podríamos llamar una aleturgia, una manifestación de la verdad
(FOUCAULT, 2010, p. 185).

Para Vanessa Lemm el asunto de la verdad en Foucault toma como paradigma a los cínicos en la medida en que en estos la encarnación cínica de la verdad deshace la «autoinmunidad» de la pólis, en donde: “en la vida de la zoe, es decir, el bíos de la zoe,

\begin{tabular}{|l|l|l|l|l|}
\hline Q Rovista Dialectus & Ano 4 & n. 11 & Agosto - Dezembro 2017 & p. 11-28 \\
\hline
\end{tabular}


el bios no se le impone a la vida animal (zoe) como una segunda naturaleza, sino que la zoe genera un bios a partir de sus propios recursos" (LEMM, 2013, p. 19). En los cínicos la verdad es rectitud en conformidad al logos, es decir la vida conforme con la ley natural, de la verdad pura y sin mezcla que no requiere suplementos a la independencia bajo la forma de la pobreza y el autogobierno. Finalmente, se trata de la verdad de la vida idéntica a sí misma al cuidado de los demás.

En términos biopolíticos la verdad recorre tres registros: epistemológico, político y ético. En el primero, Foucault está más influido por Bachelard y Canguilhem. En el segundo por Nietzsche y en el tercero por los Cínicos. En este orden de ideas, la noción de biopolítica, en tanto «tecnología de gobierno de y sobre la vida» ensambla estos tres abordajes o miradas de la verdad, cuyos efectos no se dejan esperar, bien generando en los individuos y poblaciones auto-representaciones que cristalizan en dogmas epistemológicos que son también miradas y posturas políticas totalitarias, al igual que formas de vida individuales y cerradas (biopolítica negativa). Ya sea también, creando las condiciones para el fomento de la diversidad y pluralidad de formas de vida, de posturas políticas más democráticas y el hecho de que el individuo se experimenta a sí mismo como libre y autónomo (biopolítica afirmativa).

\section{La paradoja y la rareza en Foucault}

La investigación de Foucault es paradójica en términos de la definición formulada por Gilles Deleuze en su obra Lógica del sentido: "es lo que destruye la cordura como sentido único y, a continuación lo que destruye el sentido común como asignación de identidades fijas". (DELEUZE, 1970, p. 12). Es por esto que Foucault, desde una perspectiva genealógica que ensambla el origen como procedencia (Herknunft) y el origen como emergencia (Entstehung), plantea que el problema de su investigación en torno al poder consiste en:

\footnotetext{
Mostrar las interferencias en virtud de las cuales una serie completa de prácticas- a partir del momento en que se coordinaron con un régimen de verdad - pudo hacer que lo que no existía (la locura, la enfermedad, la delincuencia, la sexualidad, etc.) se convirtiera sin embargo en algo, algo que, no obstante, siguió sin existir (FOUCAULT, 2007, p. 36).
}

Así, por ejemplo, aquello que no existía y que ahora irrumpe en nuestro presente son realidades como el neoliberalismo y que, no es que siga sin existir en absoluto, sino que en virtud de la crisis del dispositivo gubernamental se ha sometido a desplazamientos y rectificaciones. Con la invención de este nuevo arte de gobernar no solo el modelo empresa se hace extensivo al tejido social, la educación y la salud, por

\begin{tabular}{|l|l|l|l|l|}
\hline Q Povista Dialectus & Ano 4 & n. 11 & Agosto - Dezembro 2017 & p. 11-28 \\
\hline
\end{tabular}


tan solo citar dos ejemplos actuales, sino que también hace carrera en el ideario de ser empresario de sí mismo, esto es hacerse cargo de los propios éxitos y fracasos. Por lo tanto, el carácter paradójico de la investigación foucaultiana se pone de manifiesto cuando aborda el estudio del poder desde el horizonte de las tecnologías denominadas disciplinarias y las biopolíticas, pues elabora un modo de hacer filosofía vinculado al campo político, en el que propone el ejercicio del martillo con el fin de romper con "lo dado". En este orden de ideas, "lo dado" dice relación con la solidificación o cristalización de fenómenos investigados como el Estado, el gobierno, el neoliberalismo, la población o la sociedad civil que se interpretan equívocamente como entidades o esencias en sí mismas y que, en virtud de ello, se transforman en fetiches universales. En tal sentido, a estas realidades se les dota de vida propia, como si fueran datos naturales o fenómenos sustentados en ellos mismos. Por eso, el análisis crítico llevado a cabo por Foucault consiste en "poner entre paréntesis" estos universales antropológicos para referirse, más bien, a las prácticas médicas, educativas, políticas, jurídicas, entre otras, que los engendran.

En la apuesta por el método genealógico, cuyo propósito consiste en captar la singularidad de los sucesos superando toda visión teleológica que traza milagrosamente en estos una posible evolución, se aprecia una especie de giro copernicano, porque el pensador francés asesta un fuerte golpe al paradigma ortodoxo de la historiografía: no son las figuras históricas o los objetos los que determinan las prácticas, sino las discontinuidades, en términos de cortes a la linealidad y a la causalidad histórica, las que hacen posible los objetos. Detrás de los objetos no existen esencias o identidades fijas, sino que eso que llamamos esencias han sido fabricadas pieza por pieza, hechas con las fibras de material espurio.

De cara a robustecer el carácter paradójico o del modo en que Foucault piensa la realidad socio política, es menester captarlo en dos autores, uno historiador y el otro pintor. En primer lugar, en el concepto de rareza u ocultación de las prácticas empleado por Paul Veyne en sus investigaciones históricas; en segundo lugar, en el carácter no lógico y enigmático del arte del pintor René Magritte. El concepto de "rareza", que atribuimos en esta reflexión a Foucault, fue usado en principio por Georges Ville y después reactivado por el historiador Paul Veyne cuando investiga desde el punto de vista histórico la desaparición de los combates de gladiadores en el contexto de los emperadores cristianos. A este respecto, lo que Veyne encontró en términos de una

\begin{tabular}{|l|l|l|l|l|}
\hline Q Rovista Dialectus & Ano 4 & n. 11 & Agosto - Dezembro 2017 & p. 11-28 \\
\hline
\end{tabular}


respuesta inmediata, anclada a un enfoque causal y evidente, es decir historicista, es que tal fenómeno fue producido por el mismo cristianismo, en virtud del desdén de éstos hacia un espectáculo que distraía el alma de la salvación; sin embargo, el porqué se produjo la desaparición de las prácticas de los gladiadores en la coyuntura política y religiosa en que reinaban los emperadores cristianos, está ligado más a la "rareza" o a lo que Paul Veyne dio en llamar la "parte oculta del iceberg".

Con el fin de ilustrar este punto, se parte del ejemplo de un objeto: "los gobernados", el cual no es una esencia o universal, sino que llega a convertirse en una segunda naturaleza mediante prácticas que le objetivan, de tal modo que los “gobernados" se configuran en sujetos de deberes o derechos a través de otras prácticas que pueden ser jurídicas, políticas, religiosas, entre otras. El término práctica dice relación no sólo con lo que hacen las personas, de lo cual no siempre son conscientes, porque pocas veces se las conceptualiza, sino también lo que Habermas subraya en el texto Discurso filosófico de la modernidad, al referirse a Foucault: "regulaciones de las formas de acción, y costumbres consolidadas institucionalmente, condensadas ritualmente, y a menudo materializadas en formas arquitectónicas" (HABERMAS, 1989, p. 291).

Indagar el porqué se produce la supresión y desaparición de una práctica que llegó a ser tan común en el mundo romano como lo fue la lucha entre gladiadores, es entonces preguntar por aquella práctica política sedimentada, cristalizada y, en último término, oculta con el correr del tiempo, que dentro del horizonte del Cristianismo hizo posible la supresión de los combates de gladiadores. Así, pues, Veyne logra establecer que en Roma se suscita un cambio profundo en la práctica política consistente en que el Emperador tiene que gobernar sin el Senado. En consecuencia: "los emperadores se volvieron, naturalmente cristianos, por ser paternales, y pusieron fin a las luchas de gladiadores por esta misma razón" (VEYNE, 1984, p. 207). Dicha práctica política, la del emperador que, ante la supresión de la clase Senatorial, asume una posición paternal frente a sus súbditos se oculta o invisibiliza al buscar razones metafísicas u objetivos trascendentales que la podrían determinar.

La metáfora del "témpano de hielo" permite establecer la distinción entre la parte visible y la parte oculta, los discursos y las prácticas. En otras palabras, mientras que aquello que emerge es el ropaje de la práctica, esto es la racionalización, institucionalización o ideologización, en cambio la porción oculta del iceberg es la

\begin{tabular}{|l|l|l|l|l|}
\hline Q Povista Dialectus & Ano 4 & n. 11 & Agosto - Dezembro 2017 & p. 11-28 \\
\hline
\end{tabular}


"rareza" que sostiene de forma sutil y soterrada los asuntos humanos. De allí puede comprenderse la constante tensión entre el seudo-objeto natural y la práctica, lo explícito y lo implícito, lo manifiesto y lo oculto, lo patente y lo latente, la parte emergente del iceberg y la parte oculta del mismo. Sin embargo, cabe advertir que superando el punto de vista teórico, los dos elementos o polos en tensión nunca están separados, sino que más bien forman una única unidad, son el haz y el envés de una compleja trama en la que la práctica deviene junto con el objeto que aquélla suscita. En virtud de lo anterior, para Veyne la desaparición de las luchas entre gladiadores en Roma no obedece ni al hecho de la religión del Cristianismo porque la haya prohibido ni por el humanitarismo que en el paganismo romano se suscitaba en una minoría, sino porque cambia la geografía del poder público: el Emperador se ve abocado a gobernar sin el Senado. La nueva práctica de poder público se instala en Roma como una realidad que se va invisibilizando y ocultando al modo en que la parte oculta de un iceberg es ignorada cuando la vista se fija en la parte emergente. En esta forma de investigar que hace hincapié en las prácticas ocultas (parte oculta del iceberg) está presente el método genealógico foucaultiano que quita la vista de los objetos triviales y obvios, esto es de "lo dado", para ponerla en las prácticas menospreciadas, poco valoradas o tenidas en cuenta, pero que contribuyen a esculpir dichos "objetos". De manera similar, las prácticas son desplazadas cuando no se ve más que los objetos o monumentos del discurso oficial que se adoptan como hechos incontrovertibles y naturales.

El ocultamiento de las prácticas, al decir de Dreyfus y Rabinow se explica porque en relación con el hombre: "éste no puede reflexionar sobre qué son las prácticas, precisamente porque están demasiado cerca de él y, por eso, son demasiado abarcadoras" (DREYFUS, et. al., 2001, p. 65). En este orden de ideas, Foucault procede no a partir de los hechos evidentes adoptados como verdades absolutas, sino que, precisamente, disuelve las apariencias de los fenómenos cuando convierte lo evidentemente dado en un problema. Lo manifiestamente verdadero termina siendo ocupado por una "rareza", es decir por una práctica extraña, rara, no vista. En palabras de Paul Veyne, el método que siguió Georges Ville y que retrata muy bien el camino seguido por el filósofo de Poitiers, "mediante esa revolución copernicana, ya no tendremos que multiplicar, entre objetos naturales, los epiciclos ideológicos sin conseguir, a pesar de todo, engranarnos en los movimientos reales" (VEYNE, 1984, p. 203). Cuando se comprende el concepto de "rareza" que fue empleado desde la

\begin{tabular}{|l|l|l|l|l|}
\hline Q Rovista Dialectus & Ano 4 & n. 11 & Agosto - Dezembro 2017 & p. 11-28 \\
\hline
\end{tabular}


perspectiva histórica por Paul Veyne y del cual Foucault es en cierta medida heredero, se desactiva la ilusión de un dualismo ingenuo que concibe, por un lado, objetos naturalizados ("gobernantes" "gobernados" o "infraestructura" "supraestructura") y, por otra parte, las prácticas que los engendran. Esta característica de "rareza" que hemos atribuido a Foucault también puede ser rastreada en el pintor belga René Magritte desde la perspectiva del arte. Si bien es cierto que René Magritte juega con lo conocido y oculto, lo revelado y lo secreto, el sentido y el sin sentido; sin embargo, en él es imposible lo oculto o lo manifiesto a secas, esto es quedarse solo con la "parte visible del iceberg" o con la oculta. Por eso, en la obra pictórica de Magritte el dualismo aparente se transforma en un monismo no hermético.

En el pintor belga, al igual que el filósofo francés, se aprecia una obra elusiva, asistemática, poliédrica, que renuncia a la racionalización y a ser subsumida a dualismos. En sus pinturas se atisban múltiples objetivaciones que se corresponden con lo que hace el pintor, es decir pintar. No es lo pintado lo que determina la práctica de pintar sino a la inversa, la práctica, esto es, el deseo, entendido este como los afectos que circulan y funcionan en su heterogeneidad, lo que se constituye en "rejilla" de inteligibilidad de sus pinturas. Así, por ejemplo, en "La llave de los sueños", Magritte pinta diferentes objetos acompañados por nombres que no le corresponden brinda una visión de una exótica multiplicidad que no se perturba por no tener un origen o lógica común. De este modo, la paleta de Magritte no está orientada por un télos o principio rector, sino que la clave de su pintura es la paradoja. De manera análoga a Magritte, en el filósofo francés:

Todo gira alrededor de esa paradoja (...) lo que se ha hecho, el objeto, se explica por lo que ha sido el hacer en cada momento de la historia; es equivocada la idea que tenemos de que el hacer, la práctica, se explica a partir de lo que se ha hecho (VEYNE, 1984, p. 215).

En suma, los cuadros pintados por Magritte tienen la característica de ser raros y paradójicos del mismo modo que los objetos y las prácticas lo son desde la investigación foucaultiana. Es, pues, a partir de esa rareza, manifiesta en el método de Paul Veyne y en el carácter paradójico de la pintura en Magritte que se va modelando frente a Foucault el prejuicio de considerar su particular modo de filosofar como excéntrico, extraño y aberrante.

\section{Foucault y el elogio a la franqueza}

Como lo apunta en Discurso y verdad en la antigua Grecia, para el pensador francés una persona no es más que su relación con la verdad, y tal verdad ha de ser

\begin{tabular}{|l|l|l|l|l|}
\hline Q Rovista Dialectus & Ano 4 & n. 11 & Agosto - Dezembro 2017 & p. 11-28 \\
\hline
\end{tabular}


desentrañada en función de la misma obra. En este pensador, el concepto de parresiastés, cuyo uso por vez primera se remonta a la literatura griega en Eurípides (484-407 a.c) es definido como alguien "que dice todo cuanto tiene en mente: no oculta nada, sino que abre su corazón y su alma por completo a otras personas a través de su discurso" (FOUCAULT, 2004, pp. 36-37). Una nota característica, pero paradójica de la personalidad de Foucault puede analizarse en uno de los términos que acuña: el de parresiastés, porque tal noción, entraña el riesgo para sí mismo que comporta el decir "esto", "aquello" o "lo otro", pues se trata de un decir franco, libre que adopta la forma de la crítica hacia sí mismo y hacia otros. Es por esto que en la misma vida y obra del filósofo francés también se puede señalar un ejercicio verbal que le relaciona con la verdad por medio de la franqueza. Esto se puede constatar en los cursos que impartió en el Collège de France, en donde enseñó desde 1971 hasta su muerte, en junio de 1984. En éstos, el catedrático de "Historia de los sistemas de pensamiento" se ocupó de investigaciones fragmentarias, dispersas, repetitivas y discontinuas que daban la impresión de repetir las mismas pistas e ideas con machacona insistencia. Se trataba de reuniones que se celebraban los miércoles, en donde se presentaban informes públicos. Lo que hacía este pensador era esbozar pistas de investigación, ideas, esquemas, líneas de puntos e instrumentos y no un discurso monolítico, sistemático y homogéneo que versa sobre un tema en particular.

Ahora bien, en virtud de que en el contexto de la filosofía platónica existen dos tipos de parresía, ambas cercanas a la importante distinción elaborada por este filósofo entre opinión y episteme, cabría preguntarse por los criterios que autorizan reconocer a alguien como parresiastés, pues, por una parte, quien dice lo que tiene en mente puede incurrir en el sentido despectivo o peyorativo de parloteo, de decir cosas estúpidas o peligrosas para la ciudad o, por otra, en el sentido positivo de decir la verdad. En este orden de ideas, es el mismo Foucault el que establecerá tres principios ético-políticos: el primero es el de decir lo que se piensa, pero adoptando una forma de crítica hacia sí mismo y hacia otros; en segundo lugar, el de decir con libertad, pero a tenor del deber, aquello que es ayuda para el otro; finalmente, y en tercer lugar, el de decir esto, aquello o lo otro, a pesar de que comporte un riesgo y, en último término, sea peligroso para sí mismo. Crítica, deber y riesgo son formas de ser paradójicas en la vida y obra de Foucault que pondrán de relieve su papel de filósofo, historiador y activista. Cuando el filósofo de Poitiers elabora en ciertos pasajes los rasgos esenciales del perfil del

\begin{tabular}{|l|l|l|l|l|}
\hline Qevista Dialectus & Ano 4 & n. 11 & Agosto - Dezembro 2017 & p. 11-28 \\
\hline
\end{tabular}


intelectual actual recurre a tres exigencias que configuran lo que en este escrito se entiende por crítica y que, no obstante, definen su talante filosófico, a saber: en primer lugar, poder desprenderse de sí mismo; en segundo lugar, pensar en un asunto en el que no se pensaba antes; finalmente, y en tercer lugar, "pensar diferente de lo que se piensa y percibir diferente de lo que se ve" (MUCHAIL, 2004, p. 20).

En relación con lo primero, en Foucault se encarna una actitud crítica que, aunque se nutre de autores y movimientos filosóficos que la van promoviendo, siempre estuvo atenta a examinar el alcance y la insuficiencia de ella misma. Así, por ejemplo, en dos de sus primeros trabajos que datan del año 1954: por una parte, Sueño y existencia y, por otra, Enfermedad mental y personalidad, el filósofo francés pone en duda las explicaciones naturalista y positivista de la enfermedad mental que pretenden entenderla con base en los mismos principios que explicaban la enfermedad orgánica. Dicha forma esencialista y evolucionista de explicación de procesos mentales fue superada por Foucault, en razón de los aportes de Bachelard, de la fenomenología de Husserl y Merleau Ponty, como de los planteamientos de los psiquiatras de esta misma orientación como Minkowski, y Binswanger y del existencialismo de Heidegger y Sartre. De esta manera, el carácter crítico de sus investigaciones allanan el camino fenomenológico existencial que, al poner el acento en las condiciones internas de la vivencia personal, situaban a la angustia como factor explicativo de la enfermedad mental; sin embargo, paradójicamente, más allá de la fidelidad a un movimiento filosófico o método en boga, Foucault verá dicho análisis como insuficiente, porque deja de lado elementos externos de la sociedad capitalista-burguesa que llevan a la emergencia de la enfermedad mental. A partir de esa nueva crítica, el filósofo recurrirá al análisis marxista que marcará la pauta para el estudio de la historia de la locura. El ejemplo anterior, puede ilustrar que la crítica filosófica del pensador del que nos ocupamos procuró estar lejos del dogmatismo, logrando desprenderse de explicaciones que en un primer momento fueron necesarias, pero no suficientes. De esta manera, el filósofo francés, no puso cerrojo a la comprensión de los fenómenos investigados cuando estos se presentaban iluminados por la luz de otras contribuciones filosóficas. En este orden de ideas, el talante crítico y filosófico de este autor no está en una labor de fundamentación del mundo, el conocimiento o la acción, sino en la tarea desplegada como crítica de racionalidades específicas. Siguiendo a Habermas, en su libro Discurso filosófico de la Modernidad, el filósofo alemán presenta a un Foucault cuya crítica a la

\begin{tabular}{|l|l|l|l|l|}
\hline Q Povista Dialectus & Ano 4 & n. 11 & Agosto - Dezembro 2017 & p. 11-28 \\
\hline
\end{tabular}


razón moderna pasa por un desenmascaramiento del discurso de las ciencias sociales. En este caso, la crítica se entiende como poder de desprendimiento de sí mismo o el pensar contra uno mismo, lo cual supone un apartarse de la reflexión sobre el hombre, cuyo discurso desintegrado conduce a explicaciones torpes, que lo terminan desdibujando.

Con respecto al segundo elemento, pensar de una forma nueva, se sigue lo que la investigación filosófica descubre en el campo de la historia. Así, por ejemplo, existe un doble mecanismo por el cual lo que era impensable antes del siglo XVIII, se convierte en un asunto obvio y trivial para el caso del encierro de los locos. Por una parte, la locura se objetiva, es decir se erige en una totalidad opuesta y, por ende, aberrante a la razón a través de la práctica del encierro administrativo de los locos junto a criminales y niños abandonados y del discurso médico sobre la locura, mientras que el individuo adopta la forma de subjetivación del loco mediante técnicas de poder y formas de saber. Es por esto que la crítica en Foucault no pretende fundamentar al sujeto o a la realidad desde presupuestos universales y absolutos que parecen presentarse como no problemáticos, así como tampoco busca la falsación de lo establecido, sino de hacer visible o de poner en juego las condiciones que hacen aceptable el repertorio de instituciones, creencias y valores en que nos movemos. Ahora bien, las condiciones estudiadas por el pensador francés no son a priori y universales, sino que son tanto particulares y contingentes, como históricas y accidentales. Es por esta actitud crítica que él emprende la tarea de diagnóstico del presente y elabora la pregunta por el hombre en este momento histórico al estilo kantiano. Dicho trabajo de ontología del presente se abrió desde dos tradiciones filosóficas: una analítica de la verdad que indaga las condiciones de posibilidad del conocimiento verdadero y una ontología de la actualidad que recorre el camino trazado por Hegel, Feuerbach, Marx, Weber, Nietzsche y, la Escuela de Frankfurt, de la que Foucault es deudor.

Finalmente, en relación con la crítica del filósofo francés en términos de "pensar diferente de lo que se piensa y percibir diferente de lo que se ve", existen unas implicaciones del modo de investigación: pensar los grandes relatos, el progreso, la naturaleza humana, el Estado, el Poder, la Ciencia, etc., no como esencias a las que se les rinda culto, sino dentro de un cálculo de tácticas y estrategias de poder que devienen y se construyen a posteriori. Otro aspecto que contribuye a configurar el pensamiento de Foucault es su concepción paradójica de la historia, la cual ha de rastrearse desde su

\begin{tabular}{|l|l|l|l|l|}
\hline Q Rovista Dialectus & Ano 4 & n. 11 & Agosto - Dezembro 2017 & p. 11-28 \\
\hline
\end{tabular}


interlocución con dos tradiciones historiográficas: por una parte, la historia de la ciencia cuyos abanderados son Koyré y Bachelard, Serres y Canguilhem y, por otra parte, la historia social, ligada a la Escuela de los Annales, cuyos representantes más insignes son Braudel, Furet, Le Roy, Ladurie, Duby, Flandrin, entre otros.

Ahora bien, en la configuración del discurso contra histórico del pensador de Poitiers, éste encontrará las líneas de fuerza de sus propias investigaciones en la genealogía de Nietzsche y en los historiadores de la ciencia como Bachelard y Canguilhem de los que toma las ideas de ruptura y desplazamientos. Así, por ejemplo, en relación con el aporte del primero de estos autores de cara al estudio de la enfermedad mental, Foucault pasa, como ya se señaló, de una explicación fenomenológica que pone de relieve los contenidos de la experiencia vivencial del paciente a una explicación de la locura que obedece a prácticas institucionales que han perdurado hasta la posteridad y se han cristalizado en formas de discurso. De la misma manera, el pensamiento del profesor del Collège de France, bebe y es heredero del camino abierto por Fernand Braudel, quien junto con Marc Bloch, Lucien Febvre, Henri Pirenne conforman lo que desde la historiografía francesa se ha dado en llamar "los Annales". La influencia de los Annales en el trabajo del filósofo del que nos ocupamos se hará patente en la década de los sesenta, y en particular en los escritos que van de 1964 a 1971, de tal manera, que, esto configura la plataforma crítica desde la que Foucault toma distancia frente a la historiografía tradicional y al estructuralismo, al tiempo que debate de manera decisiva con el proyecto filosófico de Jean Paul Sartre. En suma, Foucault asesta un duro golpe al enfoque tradicional de la historia que considera al acontecimiento como un eslabón que, al abstraerse de una cadena que va trazando evolutivamente una trayectoria homogénea y lineal, termina por ser revestido de un aura especial que le conduce secretamente hasta su fin o realización. Por lo tanto, tal visión teleológica, metafísica y evolutiva se inscribe en una posición ingenua que considera que las ideas, las palabras, los deseos y las cosas permanecen en una burbuja que les hace inmune a luchas, disfraces y astucias. Es por esto que Foucault, siguiendo a Nietzsche, rechace el postulado de la historia tradicional, positivista y empirista en cuanto a la búsqueda del origen, pues se quiere creer que en su comienzo las cosas eran perfectas y el origen sería el lugar de una verdad solidificada por el paso del tiempo; sin embargo, para este filósofo no se trata de descalificar la historia sino de escucharla para que nos enseñe a reír de las solemnidades del origen.

\begin{tabular}{|c|c|c|c|c|}
\hline Qevista Dialectus & Ano 4 & n. 11 & Agosto - Dezembro 2017 & p. $11-28$ \\
\hline
\end{tabular}


En conclusión, el modo paradójico de hacer filosofía de Foucault, cuya imagen más representativa, quizás, es la del cangrejo, pone el énfasis en la "parte oculta" de fenómenos como el Estado, el mercado, la locura, la sexualidad, el poder y la verdad, entre otros. Lo paradójico en Foucault es que sus reflexiones no parten de lo evidente o de los hechos como realidades fijas como si pudiera trazarse sobre estos una ley que, desde afuera, les pudiera dotar de sentido, sino de prácticas heterogéneas, específicas, contingentes e históricas que contribuyen a la naturalización de dichos fenómenos. La investigación paradójica y "rara" del pensador francés que procede por rupturas y discontinuidades conduce a entender nuestro presente y aquello que somos dentro de una perspectiva crítica que pregunta por las tecnologías y dispositivos políticos de poder que históricamente han contribuido a forjar nuestra subjetividad. Lo paradójico consiste también en comprender la verdad y el saber dentro de complejos juegos de poder y en comprender el ethos del pensamiento de Foucault filósofo, historiador y activista como aquel que emula la actitud del parresiastés: que dice lo que piensa adoptando una forma de crítica hacia sí mismo, que dice con libertad, pero con arreglo al deber y que dice "esto" o "aquello" a pesar del riesgo que pueda correrse.

\section{REFERÊNCIAS:}

DELEUZE, GILLES. Lógica del sentido, Barcelona: Editorial Bote de vela, 1970.

FOUCAULT, MICHEL. La volonté de savoir. Histoire de la sexualité. Gallimard, 1976.

FOUCAULT, MICHEL. Dits et Écrits. Paris: Gallimard, Tomo IV, 1994.

FOUCAULT, MICHEL. Tecnologías del yo, Barcelona: Paidós., 1996.

FOUCAULT, MICHEL. "La ética del cuidado de sí como práctica de la libertad". En Obras esenciales. Volumen III: Estética, ética y hermenéutica. Barcelona: Paidós, 1999.

FOUCAULT, MICHEL. Defender la sociedad, Buenos Aires: Fondo de Cultura Económica, 2001.

FOUCAULT, MICHEL. Discurso y verdad en la antigua Grecia, Barcelona: Ediciones Paidós, 2004.

FOUCAULT, MICHEL. Nacimiento de la biopolítica, Buenos Aires: Fondo de Cultura Económica, 2007.

FOUCAULT, MICHEL. El Coraje de la verdad, El gobierno de sí y de los otros II. Curso en el Collège de France (1983-1984). Buenos Aires: Fondo de cultura económica, 2010.

\begin{tabular}{|l|l|l|l|l|}
\hline Q ovista Dialectus & Ano 4 & n. 11 & Agosto - Dezembro 2017 & p. 11-28 \\
\hline
\end{tabular}


HABERMAS, JÜRGEN. El discurso filosófico de la Modernidad, Madrid: Taurus, 1989.

HUBERT, DREYFUS, RABINOW, PAUL. Michel Foucault: más allá del estructuralismo y la hermenéutica, Buenos Aires: Nueva Visión, 2001.

HURTADO, VALERO. Michel Foucault, Granada: Ágora, 1994.

LEMM, VANESSA. "La encarnación de la verdad y la política de la comunidad: Foucault y los cínicos". Revista Anales del Seminario de Historia de la Filosofía, Vol. 30, núm. 2 (2013): 527-544.

MUCHAIL, SALMA TANNUS. Foucault, simplesmente, São Paulo: Loyola, 2004.

ORTEGA, FRAnCISCO. Para uma Política da Amizade, Arendt, Derrida, Foucault. Río de Janeiro: conexões, Relume Dumará, 2000.

REVEL, JUDITH. Foucault: Conceitos Essenciais. São Carlos: Claraluz, 2005.

VÁZQUEZ GARCÍA, FRANCISCO. Foucault, La historia como crítica de la razón. Barcelona: Montesinos, 1995.

VERNEAUX, ROGER. Historia de la filosofía Moderna, Barcelona: Herder, 1989.

VEYNE, PAUL. Cómo se escribe la historia. Foucault revoluciona la historia, Madrid: Alianza Universidad, 1984. 